\title{
ENSAIO SOBRE A CONCILIAÇÃO NO PROCESSO PENAL PREVISTA NA LEI DOS JUIZADOS ESPECIAIS CRIMINAIS (LEI N 9099/95)
}

\author{
Luma Gomes Gândara ${ }^{1}$ \\ João Carlos Fazano Sciarini
}

\section{RESUMO}

O presente trabalho reflete, a partir de um novo olhar do processo penal, a possibilidade de conciliação entre as partes, principalmente após o surgimento da Lei no ${ }^{\circ}$.099/95 que instituiu os Juizados Especiais Criminais para processar e julgar as infrações penais de menor potencial ofensivo. Trata-se sobre a possibilidade de conciliação neste rito processual, pormenorizando a composição civil dos danos e a transação penal e, ao final, reflete-se acerca das vantagens advindas da solução altruísta dos litígios para os envolvidos, alicerçado sob o prisma do princípio da dignidade da pessoa humana.

PALAVRAS-CHAVE: Juizado Especial Criminal. Conciliação. Composição Civil dos danos. Transação Penal. Dignidade da Pessoa Humana.

\section{TEST ON THE CONCILIATION IN THE CRIMINAL PROCEEDINGS LAID DOWN IN THE LAW OF SPECIAL CRIMINAL JUDGES (LAW N 9099/95)}

\begin{abstract}
The present work reflects, from a new perspective of the criminal process, the possibility of conciliation between the parties, mainly after the appearance of Law 9.099 / 95, which instituted the Special Criminal Courts to process and adjudicate criminal offenses of lesser offensive potential. It deals with the possibility of conciliation in this procedural rite, detailing the civil composition of the damages and the criminal transaction and, at the end, it reflects on the advantages of the altruistic solution of the litigation for those involved, based on the prism of the principle of dignity of human person.
\end{abstract}

KEYWORDS: Special Criminal Court. Conciliation. Civil Composition of damages. Criminal Transaction. Dignity of human person.

\section{INTRODUÇÃO}

No processo penal comum, prevalece o princípio da obrigatoriedade de instauração da ação penal pública, ou seja, não há para o Estado a faculdade de escolher sobre atuar ou não em casos de crimes praticados por brasileiros ou estrangeiros no território nacional.

\footnotetext{
${ }^{1}$ Mestranda em ciência jurídica pela UENP; possui especialização em Direito Civil e Processo Civil pelo Projuris/FIO (2016); possui graduação em Direito pela UENP (2014); Escrevente Técnica Judiciária no TJSP, lotada na 2 $2^{\mathrm{a}}$ Vara Cível de Assis - SP; e-mail: lgandara@tjsp.jus.br

${ }^{2}$ Advogado, Especialista em Direito Civil e Processual Civil pela UEL (2013), Especialista em Direito do Trabalho e Direito Previdenciário pela FEMA (2018). Possui graduação em Direito pela FEMA (2011), email: jcsciarini@gmail.com
} 


\section{Luma Gomes Gândara \& João Carlos Fazano Sciarini}

A possibilidade de conciliação no processo penal é temática recente, advinda principalmente após a Lei $\mathrm{n}^{\circ}$ 9099/95, que instituiu os Juizados Especiais e que permitiu tanto a conciliação entre o autor dos fatos e a vítima - composição civil dos danos - como a conciliação entre autor dos fatos e Ministério Público - transação penal.

A transação penal consiste em um pacto feito pelo Ministério Público e o autor do fato delituoso, por meio do qual é feita uma proposta de aplicação imediata de pena restritiva de direitos ou multa, distanciando-se, assim, da instauração do processo, desde que o acordo seja cumprido corretamente.

A composição civil dos danos ocorre entre a vítima e o autor dos fatos, tratando-se de crimes de ação penal privada ou de crimes de ação penal pública condicionada à representação, caso em que, sendo frutífero o acordo entre as partes, há a renúncia ao direito de apresentar queixa-crime ou representação.

A hipótese de conciliação no processo penal mitiga o princípio da obrigatoriedade, dando-lhe uma nova roupagem, passando inclusive a ter novas denominações: princípio da discricionariedade regrada ou princípio da obrigatoriedade mitigada.

Assim, a temática será introduzida pela ótica do direito penal, direitos humanos fundamentais e neoconstitucionalismo, passando ao estudo da possibilidade de pacificação no processo penal para, ao final, tratar das vantagens advindas da forma conciliada.

O método científico utilizado será o dedutivo - ligando-se as premissas com conclusões -, sendo que o estudo será realizado por meio de pesquisa bibliográfica em livros, artigos de revistas (periódicos), documentos eletrônicos, legislação e enunciados proferidos acerca do tema, objetivando-se a completude de ideias e reflexão acerca dos assuntos tratados.

Serão utilizadas como técnicas de pesquisa, de forma a coletar e examinar os materiais analisados, a pesquisa indireta documental e bibliográfica, por meio de doutrinas e artigos acerca dos assuntos a serem trabalhados.

\section{DIREITO PENAL, DIREITOS HUMANOS FUNDAMENTAIS E NEOCONSTITUCIONALISMO}

O direito penal é um ramo do ordenamento jurídico que se preocupa com os crimes e comina penas ou medida de segurança àqueles que realizarem tais condutas. 
O ius puniendi - direito de punir - é uma das atividades que o Estado toma para si na missão de reestabelecer a ordem jurídica e social quando se verifica a ocorrência de algum ilícito. Assim:

a finalidade mediata do processo penal se confunde com a do Direito Penal, ou seja, é a proteção da sociedade, a paz social, a defesa dos interesses jurídicos, a convivência harmônica das pessoas no território da nação. $\mathrm{O}$ fim direto, imediato, é conseguir, mediante a intervenção do juiz, a realização da pretensão punitiva do Estado derivada da prática de uma infração penal, em suma, a realização do direito penal objetivo (MIRABETE, 2000, p. 39-40).

Os demais ramos do Direito como civil, administrativo e tributário também protegem bens jurídicos e são menos ofensivos àqueles que os lesionam, por isso comumente se diz que o direito penal é a ultima ratio, ou seja, é a última opção quando frustradas ou ineficazes as demais áreas jurídicas, de modo que só deve ser acionado em último caso, devido ao seu alto potencial punitivo, que pode chegar a restringir a liberdade do indivíduo.

O direito penal se apresenta então como "instrumento do poder repressor do Estado, visando à tutela de bens jurídicos, a segurança de seus cidadãos e a preservação do próprio Estado, atento à manutenção da ordem pública via controle social” (DISPOSTI, 2011, p. 18).

Portanto, no processo penal, em regra, vige o princípio da indisponibilidade ou obrigatoriedade, o que torna a jurisdição necessária, sendo vedada a espontânea solução do conflito, é a regra nulla poena sine judicio:

em certas matérias não se admitem exceções à regra da proibição da autotutela, nem é, em princípio, permitida a autocomposição para a imposição da pena. É o que sucedia de modo absoluto em matéria criminal (ordem jurídica anterior à lei 9.099/95, de 26.9.1995). (CINTRA, GRINOVER, DINAMARCO, 2011, p. 37).

Contudo, pós-segunda guerra mundial, houve uma releitura de valores e a preocupação com os direitos humanos, que têm como objetivo principal assegurar o respeito à dignidade da pessoa humana. Assim:

Os direitos humanos (absolutos ou relativos) se positivam, nas Constituições, como direitos fundamentais. Assim, os direitos fundamentais possuem um sentido mais preciso e estrito, na medida em que descrevem o conjunto de direitos e liberdades jurídica e institucionalmente reconhecido e garantido pelo direito positivo. O catálogo de direitos constitucionais pode conter, junto dos direitos humanos, outros direitos considerados fundamentais (CAMBI, 2016, p. 39). 


\section{Luma Gomes Gândara \& João Carlos Fazano Sciarini}

Os direitos humanos podem ser entendidos como os direitos da pessoa humana que transcendem uma ordem jurídica específica, sendo considerados universais, ou seja, transcendem além das fronteiras de um país, isto é, pertinente a toda ordem internacional. Por outro lado, os direitos fundamentais são aqueles direitos reconhecidos dentro do ordenamento jurídico constitucional de determinado país e positivados na Constituição.

As Constituições propõem-se a proteger, sobretudo, a dignidade da pessoa humana, sendo este o núcleo de maior valor no ordenamento constitucional, noutros termos, "a Constituição, antes de qualquer medida protetiva, deve preocupar-se com os seres humanos. A dignidade da pessoa humana tem de ser o núcleo axiológico da tutela constitucional" (CAMBI, 2016, p. 38).

Mais ainda, hoje se vislumbra uma tendência neoconstitucional, que se preocupa com a efetividade dos direitos fundamentais positivados e não apenas com sua previsão. Trata-se de verdadeira superação de paradigma:

O neoconstitucionalismo se propõe a superar o paradigma da validade meramente formal do direito, no qual bastava ao Estado cumprir o processo legislativo para que a lei viesse a ser a expressão jurídica. Com isso, o direito deve ser entendido dentro das respectivas relações de poder, sendo intolerável que, em nome da "vontade do legislador", tudo que o Estado faça seja considerado legítimo. Estreitam-se, pois, os vínculos entre Direito e Política, na medida em que conceitos como os de razoabilidade, senso comum, interesse público etc. são informados por relações de poder. (CAMBI, 2016, p. 37).

Portanto, toda cautela com a dignidade da pessoa humana, seja do réu (assim entendido apenas enquanto acusado, réu propriamente dito ou já condenado), seja da vítima, é de extrema importância, já que este princípio garante e exige que toda pessoa esteja assegurada de seus direitos sociais e individuais.

Assim, qualquer ato jurídico praticado no Estado Democrático Brasileiro deve possuir como finalidade mediata ou imediata a promoção ou proteção da dignidade humana (RODRIGUES e RODRIGUES, 2017, p. 64).

Com todas essas evoluções nas ordens jurídicas e com a revalorização da pessoa humana, surgiram reflexos também na esfera penal, sendo um deles a possibilidade de pacificação do conflito, especialmente entre acusado e vítima, o que antigamente não era tolerado, pois cabia somente ao Estado o poder-dever de punir. 


\section{A CRIAÇÃO dO JUIZAdO ESPECIAL CRIMINAL E A POSSIBILIDADE DE PACIFICAÇÃO DE CONFLITOS NA ESFERA PENAL}

O artigo $98^{3}$, I, da Constituição Federal prescreveu que a União e os Estados criariam juizados especiais competentes para a conciliação, o julgamento e a execução de infrações penais de menor potencial ofensivo, mediante os procedimentos oral e sumaríssimo, permitidos, nas hipóteses previstas em lei, a transação e o julgamento de recursos por turmas de juízes de primeiro grau.

Assim, em 26 de setembro de 1995 foi criada a Lei $n^{\circ}$ 9.099, que dispõe acerca dos Juizados Especiais Cíveis e Criminais, e que é de suma importância na temática da pacificação altruísta do litígio, o que já se percebe logo em seu artigo $2^{\circ}$ quando menciona que “o processo orientar-se-á pelos critérios da oralidade, simplicidade, informalidade, economia processual e celeridade, buscando, sempre que possível, a conciliação ou a transação". (BRASIL, 1995)

Outro ponto importante da Lei $\mathrm{n}^{\text {o }}$ 9.099/95, diz respeito ao artigo $72^{4}$, que traz hipótese que excetua o princípio da indisponibilidade, abrindo verdadeiramente a possibilidade de se conciliar no processo penal. Leciona Capez (2011, p. 49):

Dada a indisponibilidade dos interesses penais, a transação, forma de autocomposição, não era admitida em nosso sistema jurídico. A situação alterou-se no que concerne às infrações de menor potencial ofensivo, esfera em que, agora, admite-se esta forma alternativa de pacificação social.

Pode-se dizer que a composição civil dos danos e a transação penal são espécies de substitutivos penais, ou seja,

Constituem estratégias de política criminal formuladas com o objetivo de evitar ou reduzir os efeitos negativos do processo de criminalização ou de execução penal, mediante substituição de mecanismos formais por mecanismos informais de controle social de fatos puníveis de leve ou média gravidade, realizados por autores considerados não perigosos, sob 0

\footnotetext{
${ }^{3}$ CF/88, Art. 98. A União, no Distrito Federal e nos Territórios, e os Estados criarão: I - juizados especiais, providos por juízes togados, ou togados e leigos, competentes para a conciliação, o julgamento e a execução de causas cíveis de menor complexidade e infrações penais de menor potencial ofensivo, mediante os procedimentos oral e sumarí́ssimo, permitidos, nas hipóteses previstas em lei, a transação e o julgamento de recursos por turmas de juízes de primeiro grau;

${ }^{4}$ Lei $n^{\circ}$ 9.099/95, Art. 72. Na audiência preliminar, presente o representante do Ministério Público, o autor do fato e a vítima e, se possível, o responsável civil, acompanhados por seus advogados, o Juiz esclarecerá sobre a possibilidade da composição dos danos e da aceitação da proposta de aplicação imediata de pena não privativa de liberdade.
} 


\section{Luma Gomes Gândara \& João Carlos Fazano Sciarini}

fundamento de que a intervenção judicial produz maior dano do que utilidade (SANTOS, 2010, p. 563).

É cediço que todo trâmite processual, qualquer que seja (cível, criminal, trabalhista etc..) causa desconforto para os envolvidos, por isso essas estratégias que têm como fito evitar os efeitos negativos do processo criminal por métodos alternativos, informais e pacíficos de solução de litígios são louváveis e mais benéficas às partes do que se tem visto de muitas intervenções judiciais.

Tal criação fez com que a tradicional jurisdição, que obrigava ao processo penal litigioso entre Ministério Público e réu ou vítima e réu em qualquer hipótese, e tornava obrigatória essa acusação, cedesse espaço para a jurisdição consensual, em que se estimula a conciliação entre os litigantes, bem assim a reparação amigável do dano e busca evitar a instauração de processo.

Esse novo espaço de consenso, substitutivo do espaço de conflito, não fere a Constituição, pois ela mesma o autoriza para as infrações de menor potencial ofensivo. Não há falar, assim, em violação ao devido processo legal e à ampla defesa, os quais são substituídos pela busca incessante da conciliação. (CAPEZ, 2011, p. 581).

É possível diante de tal reflexão que se atente para o fato de que há a mitigação de um devido processo legal em todos os seus trâmites, em busca de um bem maior que é a solução pacífica da pendenga, sobretudo, pelas próprias partes.

\subsection{Conciliação penal: composição civil dos danos e transação penal}

O Juizado Especial Criminal tem competência para o processo das infrações penais de menor potencial ofensivo, consideradas como tais as contravenções penais e os crimes a que a lei comine pena máxima não superior a dois anos, cumulada ou não com multa ${ }^{5}$.

Quando se fala em infração penal de menor potencial ofensivo, entende-se como aquelas que não causam um dano tão grande quanto às demais e que também são praticadas por autores não tão perigosos, tanto que se abre a possibilidade de conciliar para tais agentes que praticam tais infrações.

\footnotetext{
${ }^{5}$ Lei no 9099/95, Artigo 61: Consideram-se infrações penais de menor potencial ofensivo, para os efeitos desta Lei, as contravenções penais e os crimes a que a lei comine pena máxima não superior a 2 (dois) anos, cumulada ou não com multa. (Redação dada pela Lei no 11.313 , de 2006).
} 
Dispõe o artigo 62, da Lei no 9.099/95, que recebeu nova redação em 09.01.2018 para acrescer a simplicidade, que:

O processo perante o Juizado Especial orientar-se-á pelos critérios da oralidade, simplicidade, informalidade, economia processual e celeridade, objetivando, sempre que possível, a reparação dos danos sofridos pela vítima e a aplicação de pena não privativa de liberdade.

Assim, nota-se uma revaloração do papel da vítima, que deixa de ser mera colaboradora da Justiça, para ostentar o papel de protagonista: seus interesses, inclusive os civis, são lembrados pelo legislador criminal.

E, com relação ao acusado, busca-se sempre a menor onerosidade possível, ou seja, aplicação de pena não privativa de liberdade, valorizando assim o princípio da liberdade - o direito de ir e vir.

Dispõe o artigo 72, da Lei n 9.099/95 que:

$\mathrm{Na}$ audiência preliminar, presente o representante do Ministério Público, o autor do fato e a vítima e, se possível, o responsável civil, acompanhados por seus advogados, o Juiz esclarecerá sobre a possibilidade da composição dos danos e da aceitação da proposta de aplicação imediata de pena não privativa de liberdade (BRASIL, 1995)

O enunciado 71 do Fórum Nacional dos Juizados Especiais explica que:

A expressão conciliação prevista no artigo 73 da Lei 9099/95 abrange o acordo civil e a transação penal, podendo a proposta do Ministério Público ser encaminhada pelo conciliador ou pelo juiz leigo, nos termos do artigo 76, $\S 3^{\circ}$, da mesma Lei (XV Encontro - Florianópolis/SC).

Então, quando se diz em conciliação no processo penal, deve-se entendê-la em seu sentido lato, que abrange a composição civil dos danos e a transação penal.

\subsubsection{Composição civil dos danos}

A conciliação judicial entre autor dos fatos e vítima ocorre nas hipóteses de ação penal privada ou de ação penal pública condicionada à representação e pode se dar em qualquer de suas formas: com concessões mútuas entre as partes (transação), com reconhecimento (submissão), desistência ou até mesmo com simples pedido de desculpas formal. Atentando-se ao fato de que a conciliação penal é sempre judicial:

No processo penal, não há a possibilidade de conciliação fora do processo. Mesmo para a transação anterior ao oferecimento da denúncia, facultada 


\section{Luma Gomes Gândara \& João Carlos Fazano Sciarini}

pelos arts. 72 e ss. da lei n. 9.099/95, haverá sempre necessidade de controle jurisdicional: trata-se de conciliação extraprocessual por natureza, mas endoprocessual pelo momento em que pode ser efetivada (audiência preliminar) (CINTRA, GRINOVER, DINAMARCO, 2002, p. 28)

A conciliação é extraprocessual por natureza por não existir processo ainda instaurado, já que a audiência é preliminar, isto é, é anterior ao processo e visa à composição pacífica pelas próprias partes, antes mesmo de existir processo e justamente com o fito de evitar sua instauração, enaltecendo a jurisdição consensuada. E, diz-se que é endoprocessual por fazer parte de um momento previsto no procedimento especial do Juizado Especial Criminal, pelo fato de ter que ocorrer sob os olhos estatais, dada à indisponibilidade, por regra e por natureza, da matéria penal.

A conciliação na esfera penal leva em consideração o fim precípuo da pacificação social com vantagem inequívoca para ambos os envolvidos. "É possível que as partes em conflito se encontrem sob forte emoção e por isto encontrem dificuldade para encarar o mesmo fato sob a ótica da parte contrária” (VANCIM e GONÇALVES, 2014, p. 320).

Ao se prever um procedimento mais simplificado e informal, as partes, que comumente estão com os ânimos ainda acirrados pós-fato, sentem-se mais a vontade, com mais liberdade e menos tensão no momento do encontro em audiência preliminar, o que facilita a obtenção da reparação dos danos sofridos pela vítima e até mesmo de uma composição entre as partes, que muitas vezes cinge-se a um pedido de desculpas formais, acordo de bem viver e de tolerância para dali para frente.

\subsubsection{Transação penal}

A conciliação entre o autor dos fatos e o Ministério Público ocorre nas hipóteses de ação penal pública condicionada ou incondicionada.

Essa conciliação, que é chamada de transação penal, é a proposta de aplicação imediata de pena não privativa de liberdade oferecida pelo presentante do Ministério Público ao autor dos fatos sempre que: não houver possibilidade de composição civil dos danos entre vítima e acusado, por não ter sido frutífero o acordo e a vítima manifestar o desejo de representar; quando a natureza do delito for de sujeição à ação penal pública incondicionada e quando o acusado preencher os requisitos do artigo $76, \S 2^{\circ 6}$.

\footnotetext{
${ }^{6}$ Lei $\mathrm{n}^{\circ}$ 9.099/95, Art. 76. Havendo representação ou tratando-se de crime de ação penal pública incondicionada, não sendo caso de arquivamento, o Ministério Público poderá propor a aplicação
} 
Como se percebe, nos casos de infração penal de menor potencial ofensivo, mesmo sobre o alicerce de provas suficientemente robustas para o oferecimento da Denúncia por parte do órgão acusatório, caso o autor dos fatos preencha os requisitos subjetivos e objetivos previstos no artigo 76 da Lei $n^{\circ}$ 9.099/95, o Ministério Público terá o dever de propor a transação penal, não tratando a temática de mera deliberação do parquet nestes casos, até mesmo em virtude de uma interpretação teleológica acerca dos princípios que fundamentam e embasam referida Lei.

Há quem critique a transação penal por esta aplicar pena ao acusado sem o devido processo legal. Contudo, entende-se, que na verdade, é um benefício ao acusado, um acordo, verdadeira transação, ou seja, o Ministério Público abre mão de oferecer Denúncia e o acusado abre mão de tentar provar sua inocência, de modo que ambos renunciam a parcelas de seus interesses, a fim de se evitar a instauração de processo litigioso, privilegiando mais uma vez a forma conciliada.

A transação exige os seguintes elementos:

1. Acordo bilateral entre as partes legitimadas, ou seja, convergência de vontades; 2. Controvérsia com respeito à relação jurídica (...); 3. Ânimo de extinguir as dúvidas, para evitar ou terminar a demanda; 4. Concessões mútuas entre as partes (GAGLIANO, 2006, p. 225)

Por isso, justamente, a palavra transação foi colocada correta e precisamente pelo legislador dado seu caráter etimológico de se tratar de negócio jurídico pelo qual as partes de uma obrigação resolvem extingui-la mediante concessões recíprocas.

Daí a relevância da adequada condução da audiência de conciliação pelo juiz ou por conciliador, conforme dispõe o artigo $73^{7}$, da Lei $n^{\circ}$ 9.099/95. Os condutores das audiências têm de ser imparciais, terem paciência para ouvir e conduzir o diálogo, de modo a não favorecer a vítima ou o réu, mas buscar verdadeiro equilíbrio ao impasse, afim de atender ambos os envolvidos. Isso serve tanto para o momento da conciliação entre vítima e acusado, quanto para a tentativa de proposta de transação penal entre acusado e Ministério Público.

\footnotetext{
imediata de pena restritiva de direitos ou multas, a ser especificada na proposta. $\quad \S 2^{\circ}$ Não se admitirá a proposta se ficar comprovado: I - ter sido o autor da infração condenado, pela prática de crime, à pena privativa de liberdade, por sentença definitiva; II - ter sido o agente beneficiado anteriormente, no prazo de cinco anos, pela aplicação de pena restritiva ou multa, nos termos deste artigo; III - não indicarem os antecedentes, a conduta social e a personalidade do agente, bem como os motivos e as circunstâncias, ser necessária e suficiente a adoção da medida.

${ }^{7}$ Lei no 9.099/95, Art. 73. A conciliação será conduzida pelo Juiz ou por conciliador sob sua orientação.
} 


\section{AS VANTAGENS DA FORMA CONCILIADA NO PROCESSO PENAL PREVISTAS NA LEI DOS JUIZADOS ESPECIAIS CRIMINAIS (LEI No 9.099/95)}

O Juizado Especial objetiva, sempre que possível, a reparação dos danos sofridos pela vítima e a aplicação de pena não privativa de liberdade, o que, sem receio em afirmar, é um avanço em matéria de direito penal brasileiro.

Sem dúvida, a Lei 9099/95 representou um marco no processo penal brasileiro, na medida em que, rompendo com a estrutura tradicional de solução dos conflitos, estabeleceu uma substancial mudança na ideologia até então vigente. A adoção de medidas despenalizadoras e descarcerizadoras marcou um novo paradigma no tratamento da violência (LOPES JR., 2012, p. 946).

Esse novo paradigma é, acima de tudo, benéfico ao acusado, por prever medidas descarcerizadoras.

Então, sempre que se estiver diante de uma infração de menor potencial ofensivo, as partes serão intimadas para comparecimento em Audiência Preliminar, que "tem como meta a obtenção da composição civil dos danos e a transação penal (aceitação da proposta de aplicação imediata de pena não privativa de liberdade).” (BONFIM, 2013, p. 704)

Percebe-se, nessa situação, que a Lei dos Juizados Especiais possui um olhar especial para com a vítima, pois "a Justiça Penal começa a se voltar para a vítima objetivando, agora de maneira eficiente, a conciliação entre as partes, com o escopo principal de tutelar os seus interesses." Até porque, realizada a conciliação e com ela vindo a reparação do dano, esta “torna supérflua a aplicação da sanção penal, pois a satisfação da vítima coincide com aquela da sociedade. Via de consequência, o interesse na persecução penal resta esvaziado, pela composição dos danos civis." (SOUZA NETTO, 2002, p. 150-151)

A preocupação central, agora, já não é só a decisão (formalista) do caso, senão a busca do diálogo e da solução para o conflito, pois:

ao ouvir as histórias, consegue-se algo que parece inviável no processo tradicional: o relato real dos fatos e os sentimentos que as pessoas vivenciaram, dentro do contexto da infração penal. É comum que o infrator não tenha conhecimento do efeito negativo e das consequências que o ato gerou nas vítimas. O contato dialógico com a expressão das emoções impacta muito mais que os rituais formais do processo. Para ambos relatar o ocorrido, sob seus pontos de vista, é a oportunidade de colocar para fora sentimentos ruins, possibilitando a entrada de outras perspectivas para o futuro (PINTO, 2017, p. 42-43) 
A vítima, finalmente começa a ser redescoberta, porque o novo sistema se preocupou precipuamente com a reparação dos danos. Em se tratando de infrações penais da competência dos Juizados Criminais, de ação privada ou pública condicionada, a composição civil chega ao extremo de extinguir a punibilidade ${ }^{8}$ (art. 74, parágrafo único). (CINTRA, GRINOVER, DINAMARCO, 2005, p. 50).

A respeito da conciliação e da transação em matéria penal, para Fernando da Costa Tourinho Filho (2009, p. 75) ocorre "a conciliação quanto à satisfação do dano e a transação quanto à aplicação da multa ou medida restritiva. A transação diz respeito à sanção criminal a ser barganhada e a conciliação, ao acordo atinente à satisfação dos danos". No entanto, entende-se que tanto a satisfação do dano, quanto a transação são formas de conciliação, cada uma com sua peculiaridade.

Dispõe o artigo 74 da Lei $n^{\circ}$ 9.099/95 que a composição dos danos civis será reduzida a escrito e, homologada pelo Juiz mediante sentença irrecorrível, tendo eficácia de título a ser executado no juízo civil competente. E, quando se tratar de ação penal de iniciativa privada ou de ação penal pública condicionada à representação, o acordo homologado acarreta a renúncia ao direito de queixa ou representação.

Desse modo, a conciliação frutífera pelas partes, homologada pelo magistrado, torna indiscutível o assunto tratado, não podendo as partes se valerem de recursos para reabrir o tema. E, como consequência lógica, faz com que a vítima renuncie ao seu direito de apresentar queixa-crime ou representar ao Ministério Público para que este ofereça Denúncia.

No que toca à transação penal, a Lei no $9.099 / 95$, no seu artigo $76, \S^{\circ}{ }^{\circ}$ disciplina que

Acolhendo a proposta do Ministério Público aceita pelo autor da infração, o Juiz aplicará a pena restritiva de direitos ou multa, que não importará em reincidência, sendo registrada apenas para impedir novamente o mesmo benefício no prazo de cinco anos. (...) $\S 6^{\circ} \mathrm{A}$ imposição da sanção de que trata o $\S 4^{\circ}$ deste artigo não constará de certidão de antecedentes criminais, salvo para os fins previstos no mesmo dispositivo, e não terá efeitos civis, cabendo aos interessados propor ação cabível no juízo cível.

\footnotetext{
${ }^{8}$ FONAJE, ENUNCIADO 113 (Substitui o Enunciado 35) - Até a prolação da sentença é possível declarar a extinção da punibilidade do autor do fato pela renúncia expressa da vítima ao direito de representação ou pela conciliação (XXVIII Encontro - Salvador/BA).
} 


\section{Luma Gomes Gândara \& João Carlos Fazano Sciarini}

Assim, quando o acusado aceita a transação penal, tal informação não consta na certidão de antecedentes criminais, que é uma certidão que informa a existência ou não de registros criminais em nome da pessoa, e isso lhe é benéfico porque, por exemplo, existem empresas que exigem certidão negativa de antecedentes criminais para a admissão de seus funcionários e, assim também o Estado o exige para posse e exercício em concurso público.

A aceitação da proposta de transação penal não importa em reincidência, o que faz com que, no caso de o autor dos fatos vir a cometer algum crime, no momento do cálculo da pena, não incida a circunstância agravante da reincidência.

Além desses benefícios legais, a transação penal tem caráter educativo e de dar genuína chance ao acusado, servindo, além disso, para sua reflexão e crescimento pessoal (maturidade), pois muitas transações penais consistem em prestações pecuniárias a serem revertidas para entidades beneficentes ou para que o autor dos fatos efetivamente vá ao supermercado e faça compras de mercadorias de cestas básicas de alimentos (ou brinquedos para crianças) e entregue nesses locais, ou ainda, consistem em prestação de serviços como limpeza em geral, de pedreiro, pintura, jardinagem, em asilos, casas que abrigam crianças sem lar, escolas carentes, APAE etc..

Portanto, vê-se que a Lei dos Juizados Especiais Criminais, inovou abundantemente o ordenamento jurídico-penal, sendo "verdadeira revolução (jurídica e de mentalidade), porque se quebrou a inflexibilidade do clássico princípio da obrigatoriedade da ação penal. Abriu-se no campo penal certo espaço para o consenso" (CINTRA, GRINOVER, DINAMARCO, 2005, p. 50) e trouxe inúmeras vantagens como as supracitadas, tanto para a vítima, quanto para o autor dos fatos.

Em síntese, com a Lei ${ }^{\circ}$ 9.099/95, foram lançadas as bases de um novo paradigma no processo penal, em que os operadores do Direito - juízes, promotores, advogados entre outros - devem tomar para si a noção de seu novo papel, de impulsionadores da conciliação.

\section{CONSIDERAÇÕES FINAIS}

Com a entrada em vigor da Constituição Federal de 1988, houve séria preocupação com a dignidade da pessoa humana e, assim, sua devida valorização, o que trouxe reflexos em diversas áreas do Direito, dentre elas a que coube o presente estudo, qual seja, a competência dos Juizados Especiais Criminais, advindos com a Lei $n^{\circ}$ 9099/95, para julgamento e 
execução das infrações de menor potencial ofensivo e os benefícios observados com a possibilidade de se conciliar para o autor dos fatos, a vítima e o Ministério Público.

Na Carta Magna, em seu artigo 129, inciso I, está a disposição constitucional que explica uma das funções institucionais do Ministério Público, dentre elas, a de promover, privativamente, a ação penal pública, na forma da lei. Trata-se da aplicação da lei penal por parte do Estado.

No entanto, viu-se que após o surgimento da Lei dos Juizados Especiais Criminais, houve a possibilidade de se conciliar no processo penal. Onde antigamente se via uma acusação obrigatória, hoje se vê espaço para a jurisdição consensual, em que se incentiva a conciliação entre as partes, bem como a reparação do dano e a busca em se esquivar da instauração do trâmite processual.

Assim, o Ministério Público seguindo os contornos fornecidos pela lei, deve propor transação penal ao acusado que praticar infrações de menor potencial ofensivo e preencher todos os requisitos legais.

Sustentado pelo princípio da obrigatoriedade regrada ou mitigada, transigir na esfera penal equivale, então, à possibilidade de disposição da ação penal, ou seja, atenua o princípio da obrigatoriedade, dando ao órgão acusatório, discricionariedade limitada, desde que saciadas as exigências legais determinadas pela Lei dos Juizados, tudo com viés de menor onerosidade, celeridade, solução pacífica de litígios e proteção à dignidade dos envolvidos.

A composição civil dos danos e a transação penal são substitutivos penais, vistas como verdadeiras técnicas de política criminal para minimizar os resultados nocivos do processo de criminalização.

O princípio da obrigatoriedade regrada segue, então, dogmas instituídos desde o advento da Constituição Federal de 1988, dando ao acusado a oportunidade de uma sanção penal menos gravosa, trazendo-lhe desta forma a não marginalização, por ter cometido um crime com baixo potencial ofensivo e, desta forma, oportunizando-lhe benefícios por não ser considerado um reincidente criminal, mantendo-lhe a dignidade inalterada, bem assim a sua liberdade.

Percebe-se também um destaque do papel da vítima, que passa a ser protagonista na situação, pois se lança todo esforço para a obtenção da composição civil dos danos. 


\section{Luma Gomes Gândara \& João Carlos Fazano Sciarini}

Portanto, a forma conciliada traz benefícios não só para o réu, que ficará sem condenação à pena restritiva de direitos ou prisão simples, mas também para a vítima, que pode receber ressarcimento e ter reestabelecida a harmonia irrompida, pois muitas vezes, qualquer pena aplicada ao acusado por si só não satisfaz a vítima.

A proposta do presente trabalho foi a de analisar o processo de construção de um paradigma de pacificação de conflitos no processo penal e suas vantagens para os envolvidos, já que nos dias atuais, prima-se pela preservação e proteção da dignidade da pessoa humana em qualquer forma que a mesma possa se manifestar.

\section{REFERÊNCIAS BIBLIOGRÁFICAS}

BRASIL. Constituição da República Federativa do Brasil de 1988. Disponível em: < http://www.planalto.gov.br/ccivil_03/constituicao/constituicaocompilado.htm >. Acesso em: 28 fev. 2018

Lei dos Juizados Especiais Cíveis e Criminais (Lei no 9.099/95). Disponível em: < http://www.planalto.gov.br/ccivil_03/leis/19099.htm >. Acesso em: 28 fev.2018

Fórum Nacional dos Juizados Especiais (FONAJE). ENUNCIADO 71 (Substitui o Enunciado 47) - A expressão conciliação prevista no artigo 73 da Lei 9099/95 abrange o acordo civil e a transação penal, podendo a proposta do Ministério Público ser encaminhada pelo conciliador ou pelo juiz leigo, nos termos do artigo 76, § $3^{\circ}$, da mesma Lei (XV Encontro - Florianópolis/SC). Disponível em: < http://www.cnj.jus.br/corregedoriacnj/redescobrindoos-juizados-especiais/enunciados-fonaje/enunciados-criminais >. Acesso em: 28 fev.2018

BONFIM, Edilson Mougenot. Curso de Processo Penal. - 8 . ed. - São Paulo: Saraiva, 2013.

CAMBI, Eduardo. Neoconstitucionalismo e neoprocessualismo: direitos fundamentais, políticas públicas e protagonismo judiciário. São Paulo: Almedina, 2016.

CAPEZ, Fernando. Curso de processo penal. 18 ed. São Paulo: Saraiva, 2011.

CINTRA, Antônio de Carlos de Araújo; GRINOVER, Ada Pellegrini; DINAMARCO, Cândido Rangel. Teoria Geral do Processo. - 18. ed. - São Paulo : Malheiros Editores, 2002.

Teoria Geral do Processo. - 21. ed. - São Paulo : Malheiros Editores, 2005.

Teoria Geral do Processo. - 27. ed. - São Paulo : Malheiros Editores, 2011. 
DIPOSTI, Vilson Aparecido. Criminologia: transtornos neuropsíquicos e imputabilidade penal. RFD - Revista da Faculdade de Direito da UERJ, v.1, n. 19, jun./dez 2011. Disponível em: $\langle$ http://www.e-publicacoes.uerj.br/index.php/rfduerj/article/viewFile/1719/1333 $>$. Acesso em: 28 fev.2018

GAGLIANO, Pablo Stolze. Novo curso de direito civil. Obrigações. $6^{\text {a }}$ Ed. São Paulo: Saraiva, 2006.

LOPES JR., Aury. Direito Processual Penal. - 9a . ed. rev. e atual. - São Paulo : Saraiva, 2012.

MIRABETE, Julio Fabbrini. Processo Penal. 10ª Ed. rev ., atual. São Paulo: Atlas, 2000.

PINTO, Simone Matos Rios. A linguagem como forma de esclarecimento dos fatos: a verdade real a partir da metodologia da justiça restaurativa. (pág. 32-50). XXVI Congresso Nacional do CONPEDI São Luís - MA. Direito penal, processo penal e Constituição I. Coordenadores: Giovanni Olsson, Valdira Barros - Florianópolis: CONPEDI, 2017. Disponível em: <https://www.conpedi.org.br/publicacoes/27ixgmd9/5v85e2ty/5uosH1iLp4YhOY76.pdf $>$. Acesso em 26 fev.2018

RODRIGUES, Alexandra Fonseca e RODRIGUES, Alexandre Manuel Lopes. A força normativa da constituição e os direitos fundamentais como centro do ordenamento jurídico penal. (pág. 57-77). XXVI Congresso Nacional do CONPEDI São Luís - MA. Direito penal, processo penal e Constituição II. Coordenadores: Hertha Urquiza Baracho, Renata Almeida Da Costa, Thiago Allisson Cardoso De Jesus - Florianópolis: CONPEDI, 2017. Disponível em:

<https://www.conpedi.org.br/publicacoes/27ixgmd9/bidi1190/OmC6qF26N31T6PsK.pdf >. Acesso em 26 fev.2018

SANTOS, Juarez Cirino dos. Direito Penal - Parte Geral. 4 ed. rev., ampl. Florianópolis: Conceito Editorial, 2010.

SOUZA NETTO, José Laurindo. Processo penal - modificações da lei dos juizados especiais criminais. $-1^{\mathrm{a}}$ ed., $3^{\mathrm{a}}$ tir. - Curitiba: Juruá, 2002.

TOURINHO FILHO, Fernando da Costa. Comentários à lei dos juizados especiais criminais. $-6^{\text {a }}$ ed. rev. e atual. - São Paulo: Saraiva, 2009.

VANCIM, Adriano Roberto e GONÇALVES, José Eduardo Junqueira. Leis dos juizados especiais anotada e interpretada - cível, criminal e fazenda pública. Leme-SP: Mundo Jurídico, 2014. 